\title{
Anisakid Nematodes of Pagellus acarne and Trachurus trachurus, from North Atlantic Moroccan's Waters
}

\author{
Lamyae Azbaid, Sadia Belcaid and El Mostafa Talbaoui \\ Institut National de Recherche Halieutique (INRH), Centre Régional de Tanger, BP 5268, Dradeb, 90000 Tanger, Maroc
}

\begin{abstract}
An epidemiological survey of anisakid nematodes was conducted on 205 specimens of horse mackerel (Trachurus trachurus) and 183 of axillary seabream (Pagellus acarne) captured in the zone between Tangier and Larache in the north Atlantic Moroccan's coasts. Three species of nematodes were morphologically identified: Anisakis simplex s.l., Hysterothylacium sp., Pseudotarranova sp. According to the season, the nematode most observed in T. trachurus was A. simplex s.l. (the highest values of prevalence $(100 \%)$, the mean intensity (48.6). Hysterothylacium sp. was the most frequent anisakid in P. acarne with $100 \%$ of prevalence and 34.46 of the mean intensity. The infestation parameters were also analyzed according to the host species length, noting a maximum of infected fish by Anisakis simplex s.1. (96\%) in samples of horse mackerel larger than $28 \mathrm{~cm}$, while in axiliary seabream, the highest prevalence of infestation by Hysterothylacium sp. (100\%) was found in fish more than $29 \mathrm{~cm}$.
\end{abstract}

Key words: Anisakid nematodes, Trachurus trachurus, Pagellus acarne, Anisakidosis.

\section{Introduction}

Eating raw or undercooked marine fish may lead to infection with several helminthes. The anisakid nematodes can be transmitted to man and fishes act as intermediate, paratenic or definitive hosts for these helminthes [1]. Three types of anisakidosis have been recognized in accordance with the causal agents implied: anisakiasis (caused by Anisakis), pseudoterranovosis (caused by Pseudoterranova) and contracaecosis (caused by Contracaecum) [2]. The implication of Hysterothylacium spp. as a potential causal agent of anisakidosis has been widely discussed [3-7].

The Atlantic Horse mackerel (Trachurus trachurus) and the axillary seabream (Pagellus acarne) are among the major fish stocks exploited by the Moroccan fleets. The axillary seabream has traditionally been one of the main target species of the bottom trawlers, longline and artisanal fishery in Morocco. The Atlantic Horse mackerel is targeted by the coastal fleet mainly trawlers and seiners. The Atlantic horse mackerel is a

Corresponding author: Lamyae Azbaid, Ph.D., research field: pathology of aquatic animals. pelagic species that lives in the water column, usually over sandy bottom in 100-200 m, but reported to 1050 $\mathrm{m}$ [5]. Trachurus trachurus feeds on small fish and planktonic crustaceans and can be infested by larvae of Anisakis spp. by the consumption of euphausiids which are intermediates hosts of these nematodes [6]. Mackerel fish is among the principals hosts of L3 larvae of Anisakis sp., with a prevalence of 80 to $100 \%$. Pagellus acarne is a demersal species, encountered on various funds, mainly sandy and sandy-muddy up to $500 \mathrm{~m}$ depth, but it is most common between 40 and $100 \mathrm{~m}$ depth [7]. It lives in a small bench near sandy bottoms; adults attend rocky and coral areas [8]. In Morocco, this species lives on sandy and muddy from 5 to 100 meters deep. It occurs in sandy mud bottoms of the continental shelf [9]. According to Fischer et al., Pagellus acarne belongs to omnivorous species predominantly carnivorous [10]. The composition of the diet depends on the seasonal abundance and availability of prey in the environment. Feeding of Pagellus acarne consists mainly in crustaceans (preferred prey), echinoderms and teleost fish, in addition to small amounts of cephalopods and polychaetes [11]. Therefore, these two species differ 
in their habitat and diet.

Despite the visible infestation of the products of the fishing and the commercial and zoonotic importance of larval anisakid infections, few studies bent over the problem of anisakidose in Morocco. Looking forward to the establishment of a national strategy estimating in a global way the problem of the parasitism of the products of the fishing, this study and others could participate in the institution of the effective control measures, while investigating the role of structuring geographical and seasonal factors on the infestation by anisakid nematodes. Such scientific studies would make possible the application of the modalities of management of fisheries based on an approach of analysis of the risk.

The present study aimed at the identification of larval anisakid worms recovered from specimens of Pagellus acarne and Trachurus trachurus in the North Atlantic Moroccan's coasts, with data on taxonomy, parasitological indexes according to the species and the size of the host fish studied and the sampling period.

\section{Materials and Methods}

Between August 2010 and July 2011, 205 specimens of horse mackerel (Trachurus trachurus, Linné, 1758) and 183 specimens of axillary seabream (Pagellus acarne, Risso, 1827) were captured in the zone between Tangier and Larache in the Moroccan north Atlantic coast, and examined to study the presence of nematodes anisakids.

Fish were measured, weighed and dissected by making an incision along the ventral line from the anus to the buccal aperture; the visceral cavity and digestive tract were examined for the presence of parasites. The muscle was removed from the spine and immersed in warm water for several minutes to facilitate the migration of the parasite to the outside of the fish.

After dissection of the individuals, encapsulated or free nematode larvae were collected from the visceral cavity, internal organs and musculature. The parasites was counted and washed in a $0.9 \% \mathrm{NaCl}$ solution. The L3 larvae of Anisakis spp. and Hysterothylacium sp. were fixed in a solution formed from 9 parts of $70 \%$ ethanol and 1 part of glycerin and then cleared in glycerin solution $99 \%$ and observed under a light microscope. Larvae were then identified according to structural features. Respect to larvae of Pseudoterranova sp., the nematode was fixed in ethanol $70 \%$ and was later cleaned in lactophenol solution for morphological studies.

We calculated parasitological indexes related to the prevalence (P), the intensity (I) and the abundance (A) in accordance with Bush et al. [12].

$$
\begin{gathered}
\text { Prevalence }=\frac{\text { Total number of infected fish }}{\text { Total number of fish examined }} \times 100 \\
\text { Intensity }=\frac{\text { Total number of parasites }}{\text { Total number of infected fish }} \\
\text { Abundance }=\frac{\text { Total number of parasites }}{\text { total number of fish examined }}
\end{gathered}
$$

Spearman's rank correlation coefficients between fish length or period of capture and prevalence and mean intensity were calculated. The correlation between the prevalence and intensity of infestation by Anisakis simplex s.1. and Hysterothylacium sp. with the size of fish hosts was tested for significance using the Mann-Whitney U-test. Statistical testing was performed using the software Statistica 6 .

Comparisons based on normal theory such as Student's $t$-test or ANOVA are usually not applicable for parasites because of the skewness of their distribution.

\section{Results}

\subsection{Localization of Anisakids Nematodes in Trachurus trachurus and Pagellus acarne Tissue}

The observation of anisakid larvae under stereoscopic microscope after dissection of host fish has allowed an initial morphological identification and the localization of these larvae:

For the nematode Anisakis simplex larvae type I, the larvae L3 was found free or encysted in spiral form in 
different organs of the two host species studied: gonads, liver, intestine, viscera, mesentery and rarely in the muscle (Fig. 1A).

Concerning Hysterothylacium sp., nematodes were recorded from the stomach, intestine and mesentery of the samples examined of both species of fish (Fig. 1B).

The five larvae of Pseudoterranova sp. were observed in the viscera of Pagellus acarne (Fig. 1C).

\subsection{Morphological Identification of Anisakids} Nematodes Observed under Optical Microscope

Anisakid larvae observed under optical microscope were identified based on morphological characteristics which they presented:

\subsubsection{Anisakis simplex s.l. larvae type I}

The cuticle is with thin transversal striation (Fig. 2D). The Anterior extremity present a dorsal and two poorly developed ventro-lateral lips with six cephalic papillae, one pair in the dorsal lip and a pair in each ventro-lateral lip. The boring tooth is below the oral aperture, between the two ventro-lateral lips (Fig. 2C). The excretory pore is opening beneath the boring tooth. The ventricle is longer than large (Fig. 2A). Ventricular appendix and intestinal ceacum are absent. Two nearly spherical rectal glands were also observed. Tail is conical and mucron is present (Fig. 2D).

\subsubsection{Hysterothylacium sp.}

L3 larvae of Hysterothylacium sp. are whitish; possess the excretory pore near the nerve ring (Fig. 3A). They have an esophagus which ends in a ventricle from that part an intestinal cecum forward (Fig. 3C). Cuticle presents a lateral alae extending along the body (Fig. 3A). Anterior extremity is with a dorsal and two ventro-lateral lips. The interlabia are elongated, each showing a deep, long itudinal groove and a boring tooth was observed (Fig. 3A). Ventricle is nearly spherical (Fig. 3C). Four subspherical rectal glands were observed, Tail is conical and mucron is present (Fig. 3B).

L4 larvae of Hysterothylacium sp. have morphological characteristics similar to those present in third-stage larvae, except for the more developed lips and the presence of a cactus-tail (Fig. 3D).

\subsubsection{Pseudoterranova sp.}

L3 larvae of the genus Pseudoterranova possess an intestinal cecum and smaller ventricle (Fig. 4B). Pseudoterranova larvae have a red-orange colour. The mouth has three lips: a dorsal one and two subventral lips (Fig. 4A). Interlabium and boring tooth are absent. Ventricle and intestinal ceacum are present. We note the absence of ventricular appendix. Mucron is present (Fig. 4C).

\subsection{Effect of Season Variation on Infection Levels}

\subsubsection{Trachurus trachurus}

The anisakid nematode most observed in this fish host is Anisakis simplex s.l.. larva type I.

The prevalence of Anisakis simplex s.l. larvae type I was $100 \%$ in September and October 2010, and from April to July 2011. However the prevalence in August 2010 was relatively low (57.7\%) because the size of individuals in the sample was small (average size: $23.63 \mathrm{~cm}$, average weight: $108.1 \mathrm{~g}$ during this period (Fig. 5).
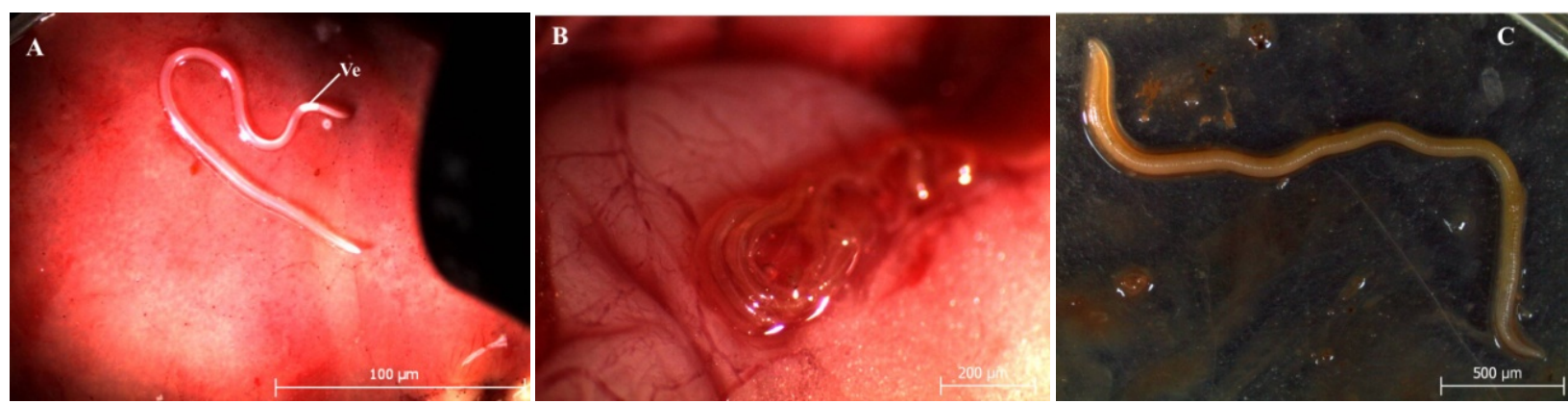

Fig. 1 Anisakid larvae. (A): Anisakis simplex s.l. L3 larvae showing esophageal ventricle. (B): Hysterothylacium sp. larvae. (C): Pseudoterranova sp. larvae. 

from North Atlantic Moroccan's Waters

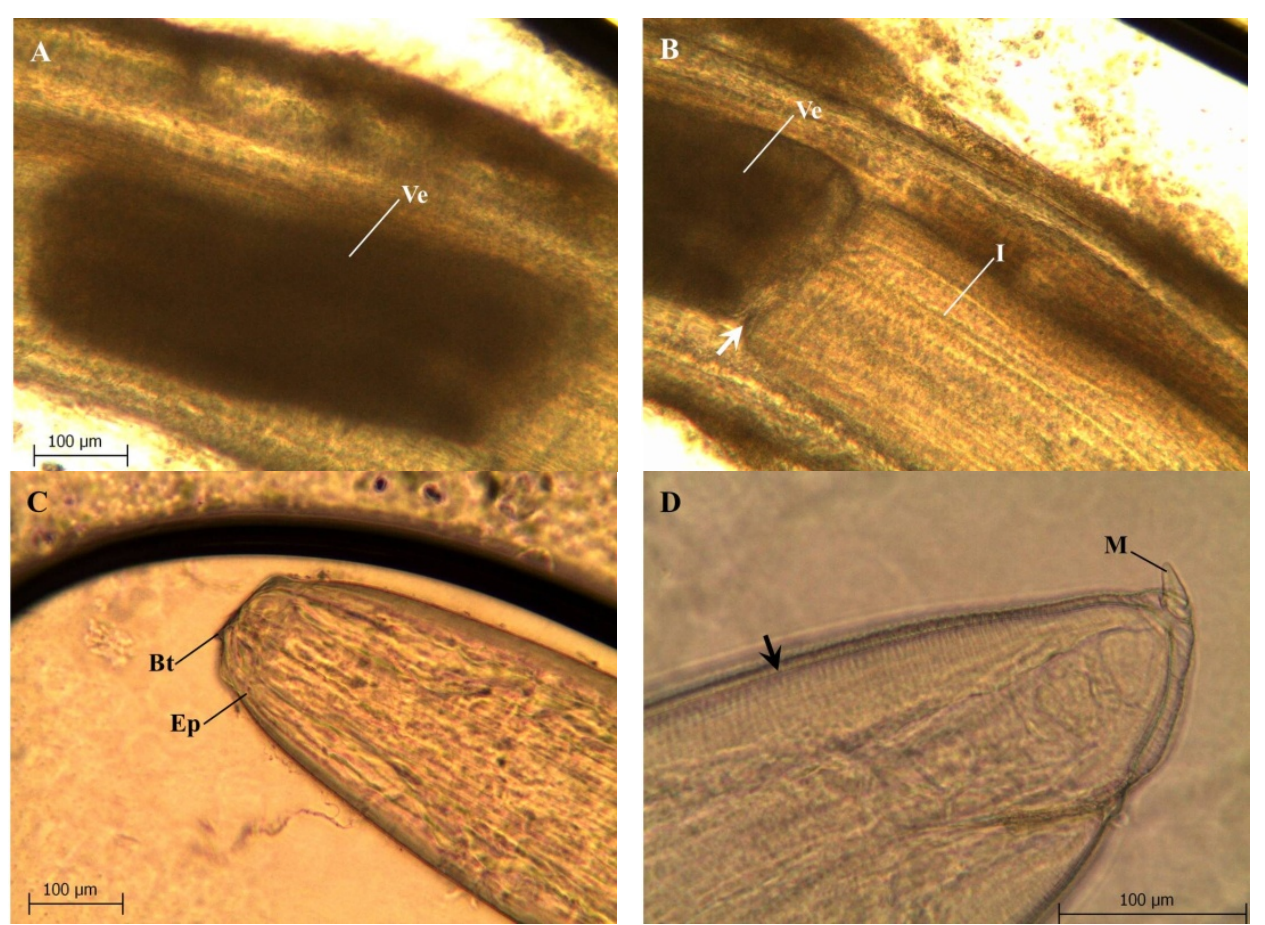

Fig. 2 Anisakis simplex s.l. L3 larvae harvested from viscera of Trachurus trachurus. (A): ventricular part showing ventricle, (B): body at the intestinal-ventricular junction level showing the oblique junction (arrowed), (C): anterior part showing excretory pore and boring tooth, (D): posterior part showing mucron and striated cuticule (arrowed). Bt: boring tooth; Ep: excretory pore; I: intestine; M: mucron; Ve: ventricle.
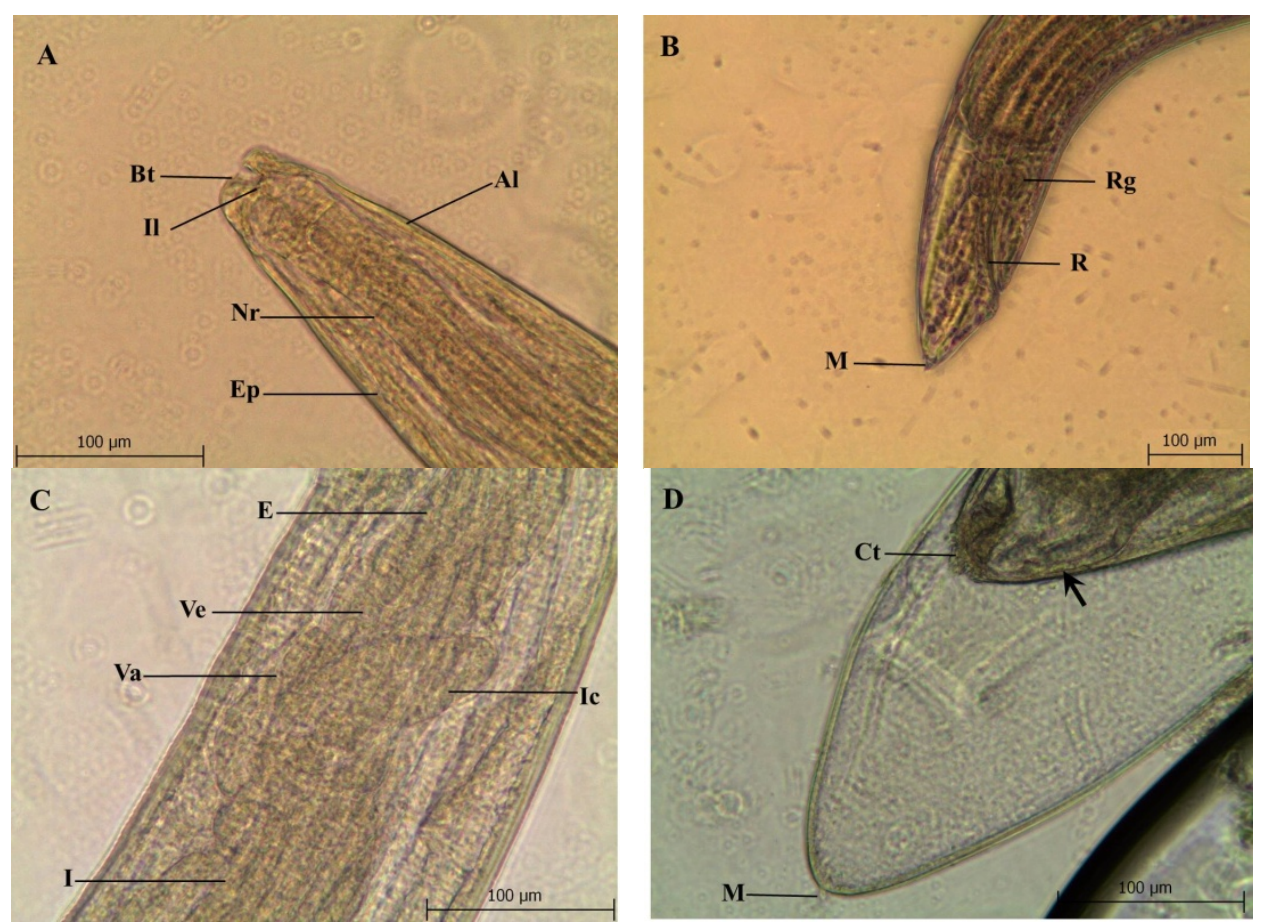

Fig. 3 L3 and L4 larvae of Hysterothylacium sp. harvested from mesentery of Pagellus acarne. (A): anterior part showing boring tooth, excretory pore just behind nerve ring, interlabium and lateral alae, (B): Posterior part of L3 larvae showing mucron and rectal glands, (C): Intestinal caecum, ventrivle and ventricular appendage of L3, (D): Posterior end of L3 larvae during moult showing L4 larvae with cactus tail. Al: lateral alae; Bt: boring tooth; Ct: cactus tail; E: esophagus; Ep: excretory pore; I: intestine; Ic: intestinal ceacum; Il: interlabium; M: mucron; Nr: nerve ring; R: rectum; Rg: rectal glands; Va: Ventricular appendage; Ve: ventricle. 
A

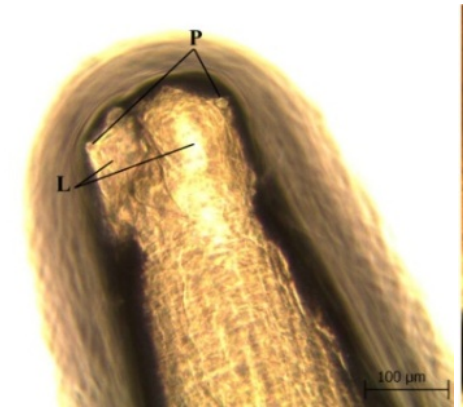

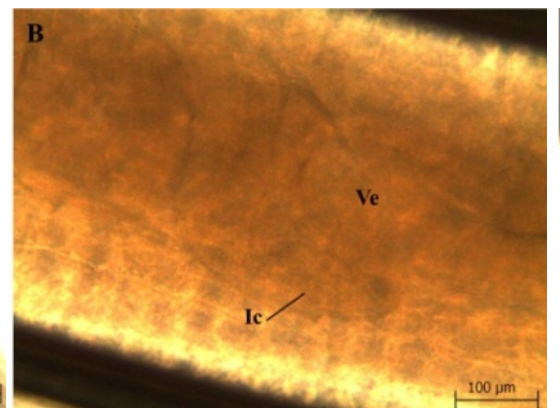

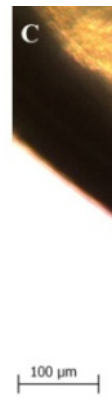

Fig. 4 Pseuderranova sp. larva harvested from viscera of Pagellus acarne. (A): Anterior part showing papilla, (B): Ventricle and intestinal ceacum of larva, (C): Posterior part with mucron. Ic: intestinal ceacum; L: lips; M: mucron; P: papilla; Ve: ventricule.

Besides prevalence, mean intensity of infection by Anisakis simplex s.l. larvae type I has also varied with the period of the study. It was more important in March and June 2011 (34 and 48.60) and less important in August 2010 (3.13) (Fig. 5).

\subsubsection{Pagellus acarne}

The anisakid nematode most observed in Pagellus acarne is Hysterothylacium sp. followed by Anisakis simplex s.l. larvae type I.

The prevalence of infestation by Hysterothylacium sp. is generally high (between $68 \%$ and $100 \%$ ). Lowest prevalences were observed in October 2010 and July 2011 (68\% and 69\% sequentially). The highest prevalences were observed the months of March, April and June 2011 (100\%) (Fig. 6).

Mean intensities of infestation by Hysterothylacium sp. varied between 3.65 and 34.46 depending on the season. The highest mean intensities were observed in December 2010 and September 2010 (34.46 and 18.18). The lowest mean intensities were recorded in March and April 2011(3.65 and 3.71) (Fig. 6).

Regarding the infestation by Anisakis simplex s.l. larva type I, the prevalence and mean intensities vary with the period of the study. The prevalence varies between $20 \%$ and $75 \%$. The highest prevalences were observed at November 2010 and February 2011 (75\% and $71 \%$ ). The lowest prevalences were found in May 2011 (20\%) and September 2010-June 2011 (31\%) (Fig. 7).

Mean intensities vary between 1.25 and 7.90. The largest mean intensities were recorded in October and
November 2010 (7.90 and 6.75). The lowest rates were noted in September 2010 and June 2011 (1.25 and 1.40) (Fig. 7).

\subsection{Variation in Infection Levels with Length}

\subsubsection{Trachurus trachurus}

Prevalence and intensity of infection grew with the increase of the total length of fish. Mean intensity of Anisakis simplex s.l. larvae type I was high in fish measuring 31-38 cm (mean intensity MI between 30 and 39) and low in fish whose length is $<26 \mathrm{~cm}$ (MI: 15 to 21 ).

Prevalence was greatest in fish which size is $>28$ $\mathrm{cm}(96 \%$ for class size $29-30 \mathrm{~cm})$ and lowest in fish measuring $<23 \mathrm{~cm}$ (Fig. 5).

\subsubsection{Pagellus acarne}

The prevalence of infection with Anisakis simplex s.l. Type I larva becomes more important with increasing size of fish hosts $(14 \%$ for sizes $<21 \mathrm{~cm}$ and $100 \%$ for sizes $\geq 31 \mathrm{~cm}$ ). Mean intensities are low for sizes $<21 \mathrm{~cm}\left(\mathrm{I}_{\mathrm{m}}=1\right)$ and are higher for fish measuring between 21 and $28 \mathrm{~cm}$ and between 31 and $34 \mathrm{~cm}$ (Fig. 6).

Regarding the most abundant nematode parasite in Pagellus acarne, the prevalence of Hysterothylacium sp. increases with the size of the host and reaches its maximum for sizes $\geq 29 \mathrm{~cm}$. The lowest prevalence $(71 \%)$ was observed for sizes $<21$ $\mathrm{cm}$. Mean intensity is low for sizes $<22 \mathrm{~cm}$ (not exceeding 3.55) and reached a value of 21 for sizes $>$ $31 \mathrm{~cm}$ (Fig. 6). 

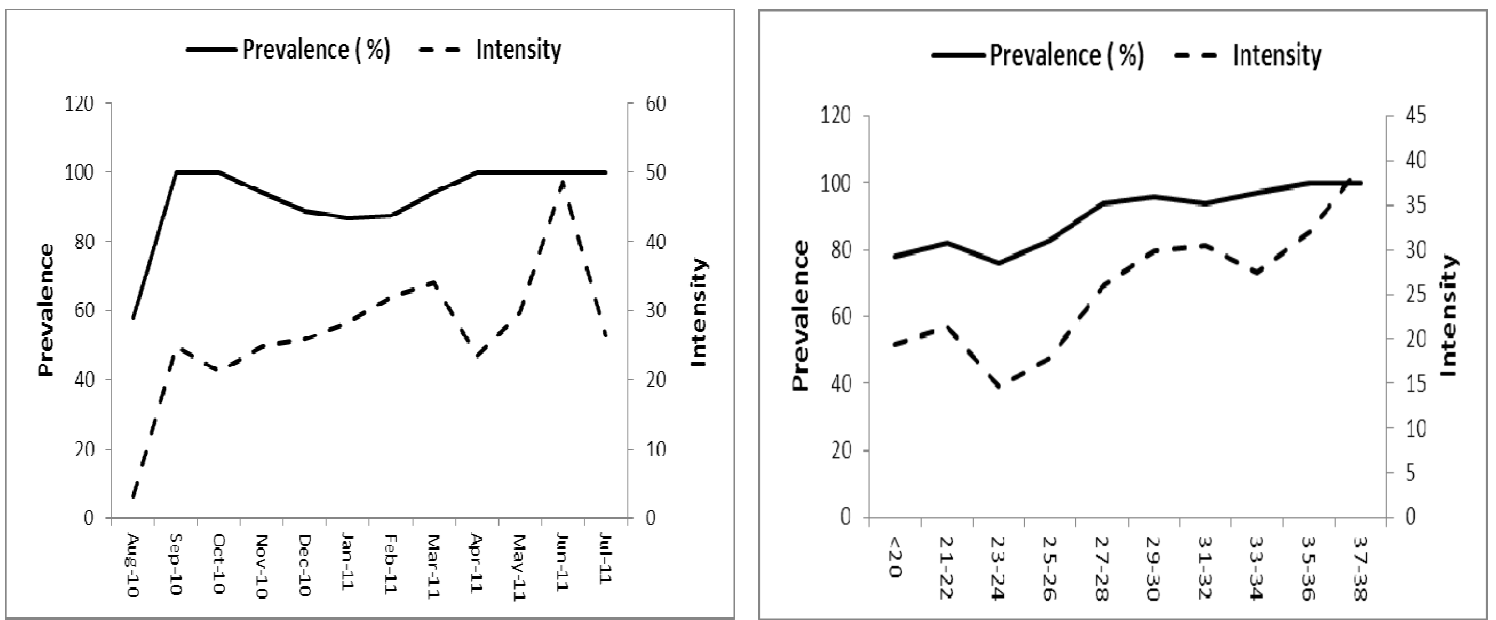

Fig. 5 Variation in prevalence and intensity of infestation of horse mackerel by L3 larvae of Anisakis simplex s.l. type I with season and length of fish host.
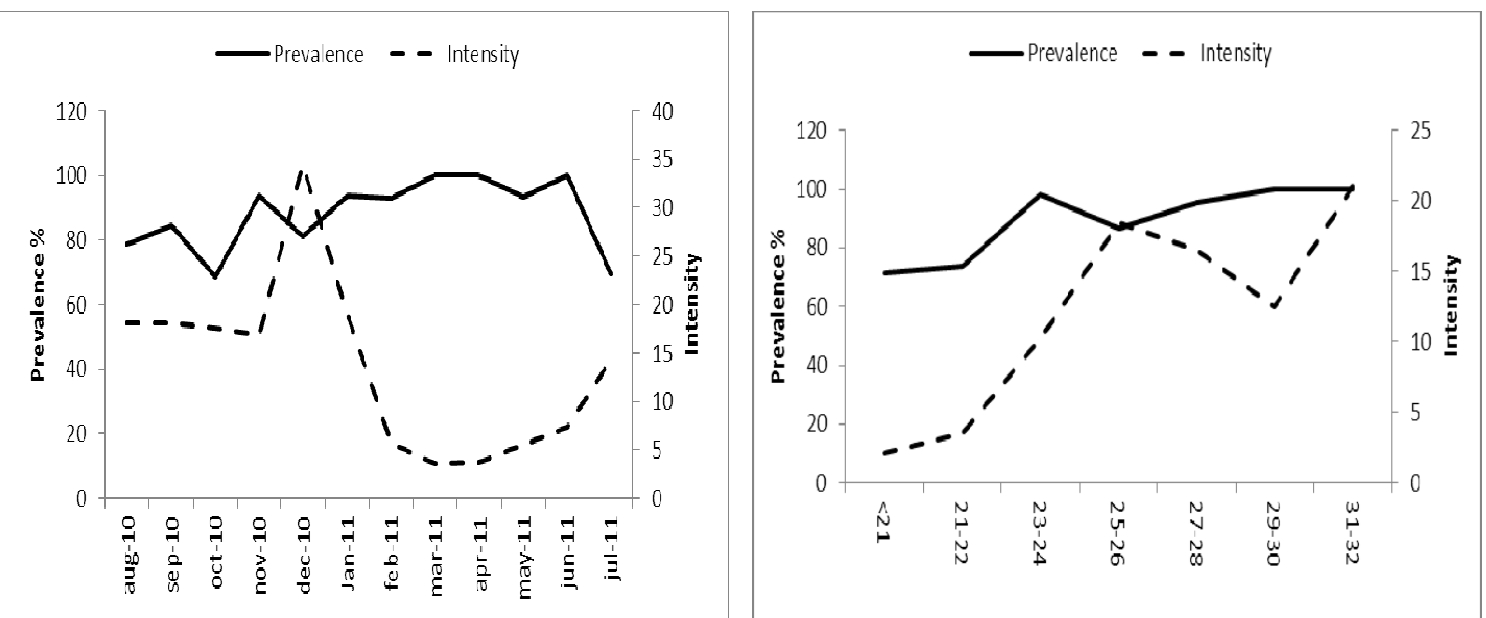

Fig. 6 Variation in prevalence and mean intensity of infestation of axillary seabream by Hysterothylacium sp. larvae with season and length of fish host.
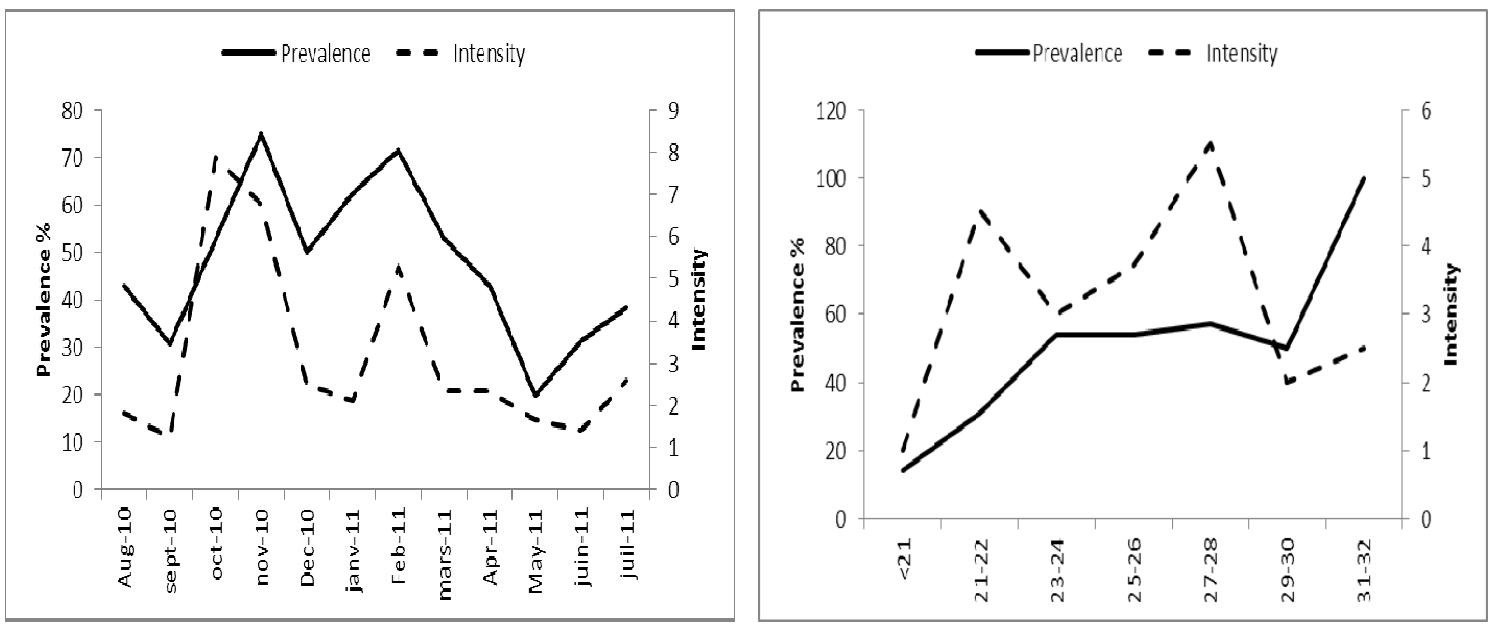

Fig. 7 Variation in prevalence and mean intensity of infestation of axillary seabream by L3 larvae of Anisakis simplex s.l. type I with season and length of fish host. 


\subsection{Statistical Analysis}

For infestation of the two species studied by L3 larvae of Anisakis simplex s.l., a positive correlation but not significant was observed between the prevalence of infestation and the size of host individuals $\left(\mathrm{R}^{2}=0.87\right.$ for horse mackerel and $\mathrm{R}^{2}=0.85$ for axillary seabream). The intensity of infestation and host size are also highly correlated in both species $\left(\mathrm{R}^{2}=0.78\right.$ and $\mathrm{R}^{2}=$ 0.86 for $T$. trachurus and $P$. acarne respectively).

Regarding infestation of Pagellus acarne by Hysterothylacium sp. larvae, significant correlation was observed between the prevalence of host size and between intensity of infection and host fish size $\left(\mathrm{R}^{2}=\right.$ 0.85 and $\mathrm{R}^{2}=0.86$ respectively).

\section{Discussions}

Larvae of Anisakid nematodes are a major problem for commercial industries of fishing, and represent a potential risk to human health, both as causative agents of anisakiasis, and as responsible of food-borne allergens $[13,14]$.

The genus Anisakis, which occurs in fish at the larval stage, was previously reported infecting Trachurus trachurus from the Mediterranean and North Atlantic costs [6-15], Sparidae as Pagellus bogaraveo from the Atlantic and Pagellus erythrinus from the Mediterranean [16, 17]. Horse mackerel may become infected with Anisakid larvae by consuming euphausiids, which are intermediate hosts of these nematodes since it is pelagic specie that eats small fish and planktonic crustaceans $[18,19]$.

Anisakid nematodes of the genus Hysterothylacium use fish as both intermediate and definitive hosts, in which they attain maturity. Some Hysterothylacium species were reported from sparid fishes, namely Pagellus acarne, Pagellus bogaraveo and a related species Diplodus sargus from the Mediterranean [16, 17, 21].

There is no evidence that Hysterothylacium larvae are pathogenic in humans or that these nematodes can even survive at human body temperature [7]. Adroher et al. reported that the optimal temperature for the survival of $H$. aduncum in vitro was $16{ }^{\circ} \mathrm{C}$ and that this nematode survived for only a few hours at $37{ }^{\circ} \mathrm{C}$ [21].

Members of the Pseudoterranova decipiens (KRABBE, 1878) species complex are the second most common nematodes found in humans (most common are nematodes of Anisakis simplex complex) $[14,22]$. Adults live in seals while their larvae in the viscera of many marine fish. This larva is commonly known as worm cod or seal worm [23].

The observation of L3 larvae of Anisakis sp. under an optical microscope showed morphological characteristics similar to those cited by Petter and Maillard (1988) and Rello-Yubero (2004), which confirms that this is the genus Anisakis [17-25].

Based on both characteristics adopted by Smith and Wootten (1978) and Rello-Yubero (2004) to differentiate the specie of the genus Anisakis, which consist of the length of the ventricle (longer than wide for Anisakis simplex and shorter for Anisakis physteris), and the presence of mucron at the end of the conical tail of the larva, we deduce that the great majority of L3 larvae that we observed corresponds to the species Anisakis simplex complex [25, 26]. Larvae are type I since the union ventricle-intestine is oblique. The larvae of Anisakis simplex complex or s.l. have a genetic but not morphological differentiation [16].

Almost all of the identified anisakid larvae in this work belonged to the A. simplex complex. This coincides with previous studies undertaken in this region [23, 27, 28], and it is related to the presence of several suitable definitive hosts, namely, several species of Delphinidae [29].

The morphological features of larvae Hysterothylacium sp. that we could detect when observed under light microscope coincide with those mentioned by Køie (1993), Shih et al. (2002), Iglesias et al. (2002), Costa et al. (2004) and Rello-Yubero (2004) $[2,16,25,30]$. 
According to Rello-Yubero (2004), the larvae of Hysterothylacium sp. that we observed have an esophagus which ends in a ventricle from that part an intestinal ceacum and a ventricular appendage [25].

According to Mattiucci et al. (2008), geographic distribution of the 5 sibling species of the $P$. decipiens complex differs somewhat [16, 23]. P. azarasi and $P$. bulbosa are found in northwestern Pacific (including Japan), P. decipiens (sensu stricto) and P. krabbei in northeastern Atlantic, $P$. decipiens (sensu stricto) in northwestern Atlantic, and P. cattani in southeastern Pacific waters. Therefore, our larvae could correspond to the species Pseudoterranova decipiens.

The intensity of infestation by Anisakis simplex s.l. and Hysterothylacium sp. was found to be positively correlated with fish length. This correlation has been detected in numerous fish species, e.g., Trachurus trachurus and Micromesistius poutassou and is rather common for parasite species that have long life spans in the host, since the fish tend to accumulate these parasites as they feed on infected prey [6, 30-32]. The parasitism indices of thus two anisakids had a positive but not significant correlation with the length and/or the age of parasitized fish from the two specie object of our study, which could be explained by an accumulation of parasites in hosts and the change of diet throughout their life $[23,33]$.

The prevalence and infestation of the fish species studied by Anisakis simplex s.l. and Hysterothylacium sp. varied with the season. According to Smith and Wootten (1978), seasonal variations in infection levels are probably due to changes in the population of infected euphausiids in the zooplankton [26].

The results obtained show that the most dominant nematode parasite differs from a host to another. For $T$. trachurus, the most nematode observed is Anisakis simplex s.1., whereas we found only five larvae Hysterothymacium sp. in this fish throughout the period of the study. This coincides with the results of [6]. When horse-mackerel samples were partitioned according to geographic origin, it became apparent that Hysterothylacium sp. were found only in horse mackerel from Mediterranean harbors [6].

Regarding P. acarne, the parasite the most found is Hysterothylacium sp. We note the infestation of Pagellus acarne by Anisakis simplex s.l. but with lower mean intensities (depending on the season, $I_{\max }$ $=7.90$ compared with $\mathrm{I}_{\max }=48.60$ for Trachurus trachurus). According to the size of the host, $\mathrm{I}_{\max }=$ 5.50 for P.acarne compared with $\mathrm{I}_{\max }=39 T$. trachurus).

This difference in parasitism of these two species may be due to their different habitats and diets. Information on the diet of Trachurus trachurus (L. 1758) in the Portuguese coast indicates that it's main diet comprises crustaceans [34]. Descriptions of the horse mackerel diet in European waters state indicate that the main food items are copepods, decapods, fish eggs and larvae, small fish and cephalopods [35]. The feeding behavior of Pagellus acarne appears to be size related, as small individuals are mostly males and live preferentially in coastal areas and shallower waters, and exhibit different feeding habits from those observed for larger individuals, which are mainly females and live preferentially at offshore banks and deeper waters. Prey composition indicated that this species have the ability to feed near the bottom on benthic prey as well as pelagic species in the water column [36]. According to Fischer et al., Pagellus acarne belongs to omnivorous species predominantly carnivorous [10].

Although the results of the stomach contents analysis for Trachurus trachurus and Pagellus acarne showed a significant feeding overlap, we suggest that they may not be sharing resources with each other, because the trophic activities of the two species are segregated by differences in habitat use. In this study, habitat partitioning appeared to be an important factor in preventing diet overlap.

In this study, a wide diversity of anisakids was detected in P. acarne from north Atlantic Moroccan's waters (Hysterothylacium sp., Anisakis simplex s.l., 
Pseudotarranova dicipiens. This diversity could be related to the wide habitat range and feeding habits of this host, which feeds on numerous benthic, benthopelagic, and pelagic species, including smaller fish, crustaceans, molluscs, and numerous other invertebrates, thus being exposed to various possible intermediate and paratenic hosts of anisakid nematodes.

\section{Acknowledgments}

I wish to thank Professor Francisco Javier Adroher and Professor Adela Valero from the Faculty of Pharmacy, University of Granada, Spain, who helped me at identifying the larvae of nematodes anisakid studied in this work.

\section{References}

[1] Anderson, R. C. 2000. Nematode Parasites of Vertebrates, Their Development and Transmission. 2nd ed. CABI Publishing, London.

[2] Iglesias, L., Valero, A., Galvez, L., Benitez, R., and Adroher, F. J. 2002. "In vitro cultivation of Hysterothylacium aduncum (Nematoda: Anisakidae) from 3rd-stage larvae to egglaying adults." Parasitology 125: 467-75.

[3] Petter, A. J. 1969. "Enquête sur les nématodes des sardines pêchées dans la région nantaise. Rapport possible avec granulomes éosinophiles observés chez l'homme dans la région." Annales de Parasitologie Humaine et Comparée 44: 25-36.

[4] Huang, W. Y. 1988. "Anisakidés et anisakidoses humaines. Deuxième partie: Enquête sur les anisakidés de poissons commerciaux du marche parisien." Annales de Parasitologie Humaine et Comparée 63: 197-208.

[5] Lloris, D., and Moreno, T. 1995. "Distribution model and association in three pelagic congeneric species (Trachurus spp.) present in the Iberic Mediterranean Sea." Sci. Mar 59 (3-4): 399-403.

[6] Adroher, F. J., Valero, A., Valero, J. R., and Iglesias, L.1996. "Larval anisakids (Nematoda: Ascaridoidea) in horse mackerel (Trachurustrachurus) from the fish market in Granada, Spain.” Parasitol Res. 82: 319-22.

[7] Coelho, R., Bentes, L., Correia, C., Gonçalves, J. M. S., Lino, P. G., Monteiro, P., and Ribeiro, J. 2005. "Age, growth and reproduction of the Axillary seabream, Pagellusacarne (Risso, 1827), from the south coast of Portugal." Thalassas 21 (1): 79-84.

[8] INRH, 2000. "Synthèse océanographique de la côte atlantique marocaine de 1994 à 1998." Travaux et document INRH 109: 121.

[9] Aloncle, H. 1973. "Catalogue raisonné des poissons des mers marocaines, douzième partie." Bulletin de l'Institut des Pêches Maritimes 21: 267.

[10] Fischer, W., Bauchot, M. L., and Schneider, M. 1987. Fiches Fao d'identification des espèces pour les Besoins de la Pêche. Méditerranée et mer noire; Zone de Pêche 37. Rome, Fao, 2: 761-1530.

[11] Rizkalla, S. I., Wadie, W. F., El-Zahaby, A. S., and EL-Serafy, S. S. 1999. "Feeding Habits of Sea Breams (Genus Pagellus) in the Egyptian Mediterranean Waters." J. KAU: Marine Science 10: 125-40.

[12] Busha, O., Lafferty, K. D., Lotz, J. M., and Shostak, A. W. 1997. "Parasitology meets ecology on its own terms: Margolis et al. Revisited." Journal of Parasitology 83: 575-83.

[13] Rohlwing, T., Palm, H. W., and Rosenthal, H. 1998. "Parasitation with Pseudoterranova decipiens (Nematoda) influences the sur vival rate of the European smelt Osmerus eperlanus retained by a screen wall of a nuclear power plant." Diseases of Aquatic Organisms 32: 233-6.

[14] Baeza, M. L., Matheu, V., Rodriguez, A., De Barrio, M., Tornero, P., Rubio, M., and Zubeldia, J. M. 2001. "Excretor y-secretor y Anisakis simplex allergens: In vivo and in vitro studies." Journal of Allergy and Clinical Immunology 107: S184.

[15] Farjallah, S., Slimane, B. B., Busi, M., Paggi, L., Amor, N., Blel, H., Said, K., and D'Amelio, S. 2008. "Occurrence and molecular identification of Anisakis spp. from the North African coasts of Mediterranean Sea." Parasitol Res. 120 (3): 371-9.

[16] Costa, G., Madeira, A., Pontes, T., and D'Amelio, S. 2004. "Anisakid nematodes of the blackspot seabream, Pagellus bogaraveo, from Madeiran waters, Portugal." Acta Parasitologica 49: 156-61.

[17] Petter, A. J., and Maillard, C. 1988. "Larves d'ascarides parasites de poissons en Méditerranée occidentale." Bulletin du Muséum d'Histoire Naturalles Paris 2: 347-369.

[18] Mattiucci, S., and Nascetti, G. 2008. "Advances and trends in the molecular systematic of anisakid nematodes, with implications for their evolutionary ecology and host-parasite co-evolutionary processes." Advances in Parasitology Journal 66: 47-148.

[19] Muus, B. J. and Dahlstrom, P. 1966. Guide des poissons de mer et pêche., Switzerland: Neuchâtel, Delachaux \& Niestlé.

[20] Smith, J. W. 1983. “Anisakis simplex (Rudolphi, 1809, det. Krabbe, 1878) (Nematoda: Ascaridoidea): morphology and morphometry of larvae from euphausiids and fish, and a review of the life-history and ecology." 

from North Atlantic Moroccan's Waters

Journal of Helminthology 57: 205-24.

[21] Petter, A. J., and Cabaret, J. 1995. "Ascaridoid nematodes of teleostean fishes from the eastern North Atlantic and seas of the North of Europe." Parasite 2: 217-30.

[22] Adroher, F. J., Valero, A., Wolff, M., and Ruiz-Valero, J. 1991. "Mantenimiento y ecdisis in vitro de Hysterothylacium aduncum." In ICASEP I, Valencia, Spain, 1-5 July, 124.

[23] Mattiucci, S., Nascetti, G., Cianchi, R., Paggi, L., Arduino, P., Margolis, L., Brattey, J., Webb, S. C., D’Amélio, S., Orecchia, P., and Bullini, L. 1997. "Genetic and ecological data on the Anisakis simplex complex with evidence for a new species (Nematoda, Ascaridoidea, Anisakidae)." Journal of Parasitology 83: 401-16.

[24] Berland, B. 1961. "Nematodes from some Norwegian marine fishes." Sarsia 2: 1-50.

[25] Rello Yubero, F. J., Francisco Javier Adroher, F. J., and Valero López, A. 2004. "Anisákidosparásitos de pecescomerciales. riesgosasociados a la saludpública." Anales de la Real Academia de CienciasVeterinariasde Andalucia Oriental 17: 173-97.

[26] Smith, J. W., and Wootten, R. 1978. "Anisakis and anisakiasis." Advances in Parasitology 16: 93-163.

[27] Sequeira, V., Gordo, L. S., Neves, A., Paiva, R. B., Cabral, H. N., and Marques, J. F. 2010. "Macroparasites as biological tags for stock identification of the bluemouth, Helicolenusdactylopterus (Delaroche, 1809) in Portuguese waters." Fish Res. 126: 321-8.

[28] Hermida, M., Mota, R., Pacheco, C. C., Santos, C. L., Cruz, C., Saraiva, A., and Tamagnini, P. 2011. "Infection levels and diversity of anisakid nematodes in blackspot seabream, Pagellus bogaraveo, from Portuguese waters."
Parasitology Research 110 (5): 1919-28.

[29] Santos-Reis, M., and Mathias, M. L. 1996. "The historical and recent distribution and status of mammals in Portugal." Hystrix 8: 75-89.

[30] Køie, M. 1993. "Aspects of the life cycle and morphology of Hysterothylacium aduncum (Rudolphi, 1802) (Nematoda, Ascaridoidea, Anisakidae)." Canadian Journal of Zoology 71: 1289-96.

[31] Cruz, C., Vaz, A., and Saraiva, A. 2005. "Larval anisakids from horse mackerel in Portugal." Helminthologia 42: 3-7.

[32] Cruz, C., Barbosa, C., and Saraiva, A. 2007. "Distribution of larval anisakids in blue whiting of Portuguese fish market." Helminthologia 44: 21-4.

[33] Hsui-Hui, S., and Ming-Shiou, J. 2002. "Hysterothylacium aduncum (Nematoda: Anisakidae) Infectinga Herbivorous Fish, Siganus fuscescens, off the Taiwanese Coast of the North West Pacific.” Zoological Studies 41 (2): 208-15.

[34] Cabral, N., and Murta, A. 2002. "The diet of blue whiting, hake, horse mackerel and mackerel off Portugal." J. of Applied Ichth 18 (1): 14-23.

[35] Olaso, I., Gutiérrez, J. L., Villamor, B., Carrera, P., Valdes, L., and Abaunza, P. 2005. "Seasonal changes in the north-eastern Atlantic mackerel diet (Scomber scombrus) in the north of Spain (ICES division VIIIc)." Journal of the Marine Biological Association of the United Kingdom 85: 415-8.

[36] Morato, T., Solà, E., Grós, M. P., and Menezes, G. 2001. "Feeding habits of two congener species of seabreams, Pagellus bogaraveo and Pagellusacarne, off the Azores (northeastern Atlantic) during spring of 1996 and 1997." Bulletin of Marine Science 69 (3): 1073-87. 